\title{
Tabbet el-Guech (Saqqara-sud, 2020)
}

\section{Vassil Dobrev}

\section{OpenEdition \\ Journals}

Édition électronique

URL : https://journals.openedition.org/baefe/2978

DOI : $10.4000 /$ baefe.2978

ISSN : 2732-687X

Éditeur

ResEFE

\section{Référence électronique}

Vassil Dobrev, «Tabbet el-Guech (Saqqara-sud, 2020) » [notice archéologique], Bulletin archéologique des Écoles françaises à l'étranger [En ligne], Égypte, mis en ligne le 30 mai 2021, consulté le 27 juillet 2021. URL : http://journals.openedition.org/baefe/2978 ; DOI : https://doi.org/10.4000/baefe.2978

Ce document a été généré automatiquement le 27 juillet 2021.

\section{cc) (†) $\odot$}

Le Bulletin archéologique des Écoles françaises à l'étranger est mise à disposition selon les termes de la Licence Creative Commons Attribution - Pas d'Utilisation Commerciale - Pas de Modification 4.0 International. 


\title{
Tabbet el-Guech (Saqqara-sud, 2020)
}

\author{
Vassil Dobrev
}

\section{NOTE DE L'AUTEUR}

Année de la campagne : 2020 ( 4 janvier - 12 février)

Autorité nationale présente : Le ministère du Tourisme et des Antiquités (MoTA) était représenté par l'inspecteur Emad Farouk sur le site, l'inspectrice Shaimaa Eltayeb au magasin, les restaurateurs Hassan Abdalla et Abu Bakr Hashem avec leurs équipes et le raïs Mohamed Antar

Numéro et intitulé de l'opération de terrain : 17122 - Tabbet el-Guech (Saqqara-sud) Composition de l'équipe de terrain : Vassil Dobrev (archéologue-égyptologue, Ifao). Partenariats institutionnels : La mission bénéficie du soutien du MoTA, du British Museum (Institute for Bioarchaeology), de l'université Paul-Valéry Montpellier 3, de l'Académie polonaise des sciences (Varsovie), et de l'American University in Cairo. Organismes financeurs : British Museum (Institute for Bioarchaeology).

1 Les travaux de la mission se sont déroulés du 4 janvier au 12 février 2020, dans l'angle sud-est du plateau connu sous le nom de Tabbet el-Guech (nord-ouest) sur le site de Saqqara-sud et dans le magasin de la mission à Saqqara. La conservation-restauration de différents éléments d'architecture funéraire dans la zone déjà fouillée $(60 \times 50 \mathrm{~m})$, surtout des tombeaux en brique crue, a été poursuivie.

\section{Complexes funéraires TG 1 et TG 3}

2 À Saqqara-sud, sur le plateau nord-ouest de Tabbet el-Guech, des prêtres égyptiens de la $\mathrm{VI}^{\mathrm{e}}$ dynastie (2300-2100 av. J.-C.) ont fait construire des tombes dont les chapelles funéraires ont été creusées dans la montagne. Ces chapelles, dont les façades en pierre sont décorées avec des reliefs, font partie des complexes funéraires nommés TG 1, TG 2, TG 3 et TG 4 (fig. 1). Avec le temps, les voûtes de certaines de ces chapelles ont été découvertes écroulées, les blocs de leurs façades éparpillés. C'était le cas des voûtes des 
chapelles $\mathrm{T} 10, \mathrm{~T} 11$ et $\mathrm{T} 12 \mathrm{du}$ complexe funéraire TG 3 , appartenant respectivement aux prêtres Khouy, Intef et Ânkh-haef, et de la chapelle T 2 du prêtre [Pépy]seneb située dans le complexe $\mathrm{TG} 1$. Après avoir restauré les blocs en calcaire des façades, nous avons commencé la restauration des voûtes écroulées des chapelles, déjà protégées par un plafond métallique.

Derrière la façade décorée d'Intef (fig. 2) se trouve sa chapelle funéraire T 11. Les travaux de restauration de sa voûte ont été poursuivis et achevés en janvier 2020.

En janvier 2020 ont débuté les travaux de restauration de la voûte de la longue chapelle T 2 (9 m) du prêtre [Pépy]seneb dans le complexe TG 1 . On envisage de continuer ces travaux en 2021.

\section{Déplacement du matériel anthropologique conservé au magasin du MoTA à Dahchour et dans les tombes sur le site de Tabbet el-Guech au magasin de la mission à Saqqara}

5 Les nécropoles successives identifiées dans la zone fouillée réduite $(60 \times 50 \mathrm{~m})$ sur un plateau de 10 ha au nord-ouest du site de Tabbet el-Guech ont livré de nombreux témoignages d'anthropologie funéraire avec des inhumations différentes: momies et squelettes avec traces de momification placés dans des cercueils en bois ou en terre cuite de types anthropomorphe, ovale et rectangulaire, ou bien dans des sarcophages en pierre calcaire avec espace intérieur anthropomorphe, squelettes enveloppés dans des nattes végétales ou placés en "pleine terre» (sable), amas et réductions d'ossements humains en " pleine terre ".

6 À peu près 200 boîtes avec ossements humains et 2 avec ossements d'animaux ont été entreposés dans la chapelle $\mathrm{T} 14$ et la cour couverte du complexe funéraire TG 3, ainsi que 5 cercueils en terre cuite avec leurs momies. Les autres 40 cercueils en bois et en terre cuite avec leurs momies se trouvaient dans le magasin du MoTA à Dahchour.

7 En janvier 2020, on a achevé le déplacement du matériel anthropologique resté entreposé dans le complexe funéraire TG 3 dans le magasin de la mission à Saqqara qui a aussi reçu les cercueils du magasin du MoTA à Dahchour en février 2020. 
Fig. 1. Plan des structures en brique crue sur le plateau nord-ouest de Tabbet el-Guech (0. Onézime).

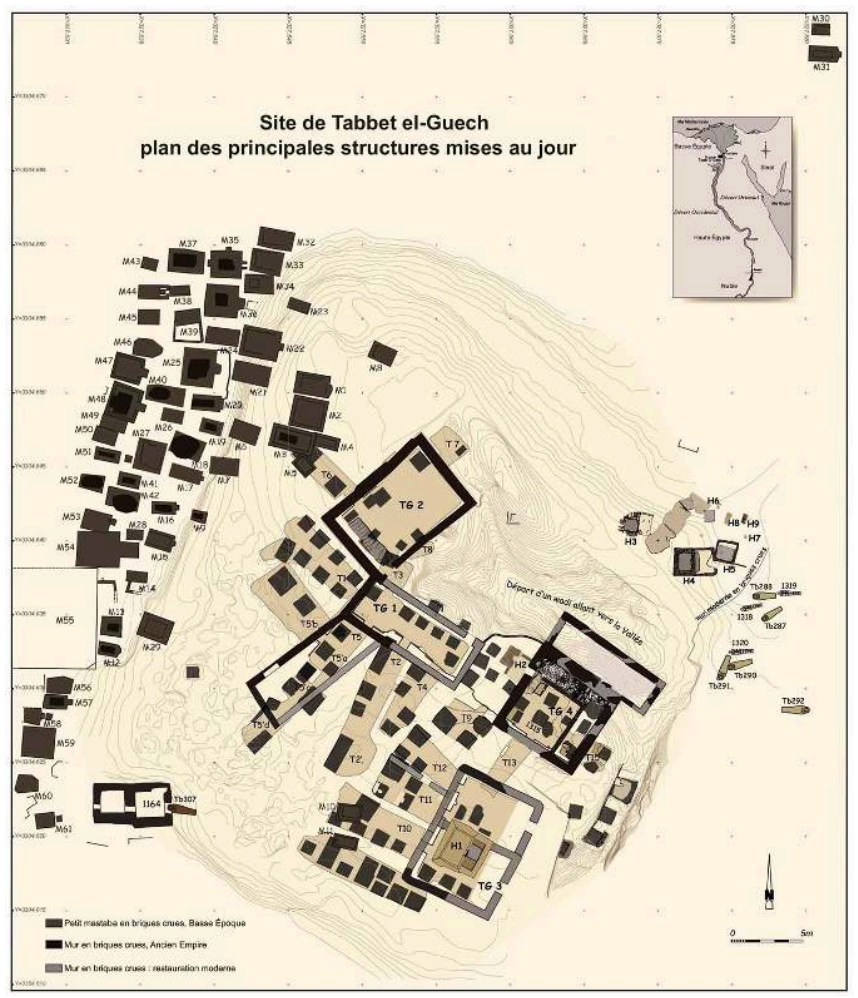

(C) Ifao. 17122_2020_NDMPF_001 
Fig. 2. Complexe funéraire TG 3 : façade décorée de la chapelle funéraire T11 du prêtre ritualiste Intef; vue de l'est vers l'ouest (V. Dobrev).

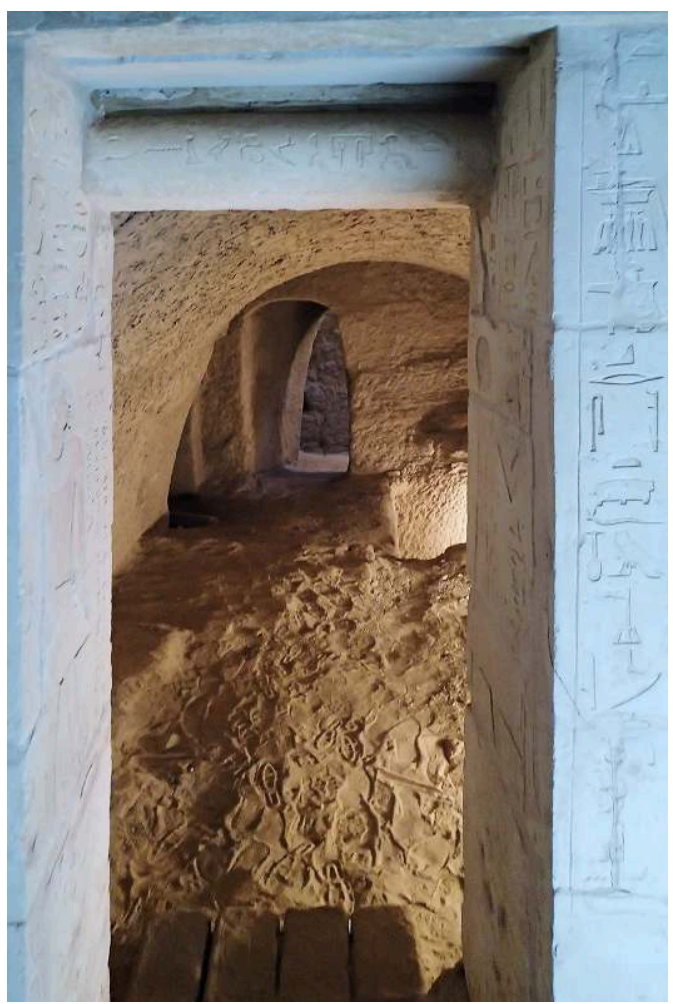

(c) Ifao. 17122_2020_NDMPF_002 
Fig. 3. Complexe funéraire TG 3 : voûte restaurée de la chapelle funéraire T11, vue de l'ouest vers l'est (V. Dobrev).

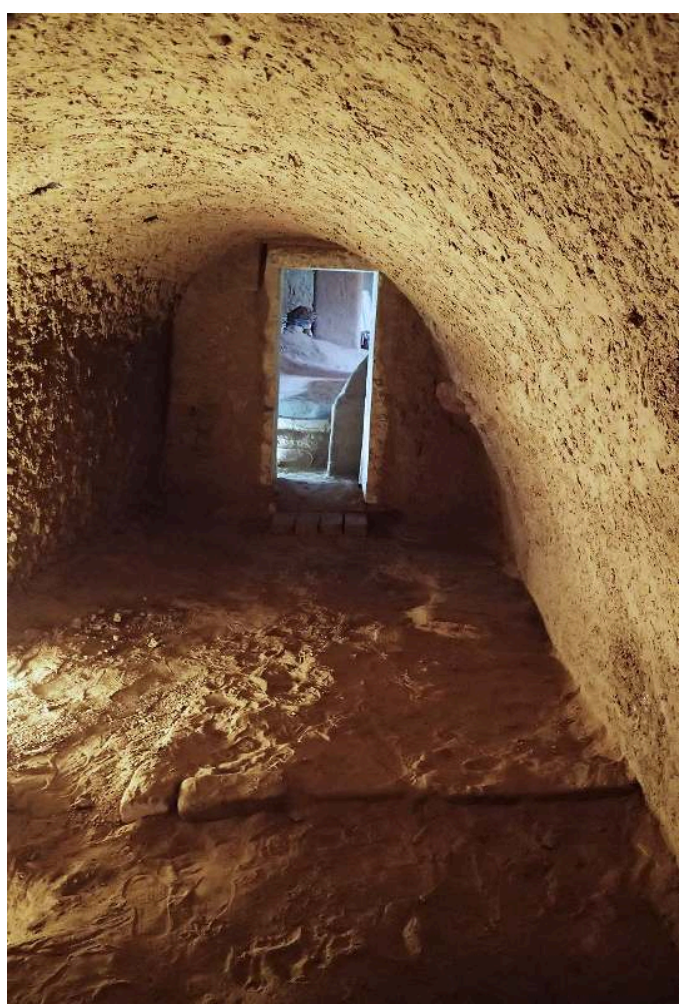

(C) Ifao. 17122_2020_NDMPF_003

\section{INDEX}

\section{Thèmes : IFAO}

Année de l'opération : 2020

lieux https://ark.frantiq.fr/ark:/26678/pcrt1w2hfQncE8

nature https://ark.frantiq.fr/ark:/26678/pcrtRXhdi4O5ST

sujets https://ark.frantiq.fr/ark:/26678/pcrtGdotYbyIR9, https://ark.frantiq.fr/ark:/26678/ pcrtrU7ImEVbLP, https://ark.frantiq.fr/ark:/26678/pcrtxAh3LEGcFT, https://ark.frantiq.fr/ ark:/26678/pcrtRXhdi4O5ST, https://ark.frantiq.fr/ark:/26678/pcrtxmcsM2Exyx, https:// ark.frantiq.fr/ark:/26678/crtiMNlD8Asde, https://ark.frantiq.fr/ark:/26678/pcrtf0jhaoDXkJ

\section{AUTEURS}

\section{VASSIL DOBREV}

Archéologue-égyptologue, Ifao 